\title{
DISCURSO POLÍTICO: LEITURAS E INFERÊNCIAS
}

\author{
Marilurdes Menezes de Lima ${ }^{1}$ \\ Diogenes José Gusmão Coutinho²
}

RESUMO: O presente artigo apresenta abordagens bibliográficas de autores que discorrem acerca de discursos políticos, como eram desenvolvidos antes e agora, qual objetivo dos mesmos e como as pessoas viam e refletiam sobre tais ações pretendidas pelos políticos. O artigo desenvolve a metodologia qualitativa e bibliográfica de estudiosos que discutem o poder do discurso político como forma de persuadir o eleitor, objetivo esse que prevalecem até hoje. O discurso político é um ato que leva o ser humano (político) a mascarar uma fala que tem como objetivo persuadir o leitor/ouvinte (eleitor) que por sua vez busca analisar as propostas de trabalho apresentadas em discurso público em períodos eleitorais para que o candidato (político) seja eleito. Não se pode negar que as propostas enchem os olhos dos eleitores que ouvem e criam ilusões com as possíveis soluções para os problemas que afligem tantos cidadãos brasileiros. Desde que o mundo existe, há a questão política. Antes o poder que muitos buscam era concentrado em apenas uma pessoa que nomeava seus súditos e governava o lugar ou nação. A política e o discurso político sempre existiram e vai continuar existindo, antes o eleitor não tinha opinião, sua vontade era ignorada, hoje o discurso viabiliza mais o eleitor, pois a liberdade de expressão e muitas outras conquistas levam o eleitor a refletir melhor na escolha de seu candidato, ainda se tem pessoas que são submissas a seus candidatos. Hoje o poder de persuasão não é tão forte quanto antes. É preciso sim, convencer o eleitor, fazer com que ele seja um disseminador das ideias que o seu candidato defende, mas com segurança de que as propostas de trabalho possam ser postas em prática realmente, uma vez que as eleições ocorrem de quatro em quatro anos, e os problemas vão se acumulados e muitas vezes são esquecidos, para serem lembrados no próximo período eleitoral. Este artigo busca a compreensão, por meio de Arendt, da diferenciação por ele estabelecida entre a fala pública referente à dominação e o discurso político e os conceitos de Patrick Charaudeau à respeito das imagens dos atores políticos entre outros conceitos de estudiosos acerca do discurso político.

Palavras-chave: Ensino. Leitura. Inferências. Discurso Político. Persuasão. Poder.

\footnotetext{
${ }^{1}$ Mestre em Educação pela UniNorte Universidade Del Norte no Paraguai (Py), professora de Língua Portuguesa da Escola EREM, Escola Estadual Benigno Pessoa de Araújo, da Escola Municipal Capela de São Sebastião e do Colégio Ágape na rede privada, na cidade de Goiana do estado de Pernambuco, participante do VII CONEDU - ONLINE - VII Congresso Nacional de Educação.

${ }^{2}$ Doutor em biologia pela UFPE. E-mail: prof.diogenesgusmao@gmail.com.
} 


\section{INTRODUÇÃO}

Sabe-se que a leitura é um instrumento que exige muito das pessoas envolvidas neste processo, estudantes, professores entre outras pessoas que também contribuem para as leituras sejam realizadas. Não é fácil formar leitores competentes, principalmente quando se tem um sistema de educação que não investe como deveria, no que tange o governo de alguns países.

São vários anos que o estudante passa em uma escola para que esse processo seja desenvolvido, no que concernem as várias disciplinas, principalmente no estudo de Língua Portuguesa. Os profissionais que atuam como professores, muitos se desdobram como podem para obterem resultados satisfatórios no ensino de leitura, visto que a leitura é fundamental para o ser humano.

O senso crítico para ser desenvolvido exige do ser humano conhecimento prévio e teorias acerca de temas que estão presentes no cotidiano das pessoas.

Dessa forma, formar bons leitores não é fácil, já que existem vários empecilhos para que tal atividade seja desenvolvida. Ainda se percebe que muitos profissionais da educação não desenvolvem leituras motivadoras, descontraídas, prazerosas para que os estudantes possam se sentir atraído pela leitura.

Os textos, em muitos momentos, são utilizados apenas como pretexto para transcrever informações que são expostas nos mesmos, não há aquela atividade que faz o aluno buscar, questionar, opinar sobre a temática abordada no texto. Ainda temos profissionais que não utilizam textos em suas aulas como deveriam. $O$ ensino de leitura não atinge o resultado almejado, ou seja, formar leitores competentes que possam fazer inferências a partir dos textos lidos.

É preciso mudar, desenvolver estratégias diversificadas e criativas envolvendo os inúmeros gêneros textuais, os quais podem ser explorados como instrumentos para estimular os estudantes, que os deixem com vontade e motivados a realizar leitura sobre qualquer assunto abordado no texto, livro, sites etc.

A leitura não está atrelada a decodificar palavras ou expressões explicitas no texto, é necessário realizar leitura de mundo e associar aos conhecimentos prévios que o leitor tenha adquirido com a vida escolar, cotidiana, etc. 
Não se devem realizar leituras repetitivas. Em muitos livros didáticos os textos não são bem visto pelos alunos, uma vez que são muito longos e não despertam no aluno o desejo de ler com gosto. Quando o aluno começa a ler e observa que uma leitura longa, ele já demonstra desmotivado e faz a leitura apenas das informações explicitas no texto sem fazer nenhuma conexão a outros assuntos que possam estar relacionados ao tema abordado no texto.

Os textos devem ser curtos para que o estudante não se perca nas informações, fazendo com que eles percebam as informações explícitas e implícitas que são as "entrelinhas de um texto". 3

O estudante já não quer ler textos dos livros didático e paradidáticos, e se for um discurso político, o interesse para lê-lo é bem menor. O ser humano quer apenas saber as informações superficiais do texto, não se preocupa com as leituras que podem ser feitas a partir do texto, pois se sabe que um mesmo texto pode ser lido, isto é, o leitor pode tirar várias interpretações as quais podem levar a mudança de comportamento do leitor. As inferências que são feitas de um texto, após lê-lo, permitirão que ele seja compreendido e interpretado coerentemente.

Uma leitura prazerosa é aquela que o leitor faz com satisfação e o professor como mediador desse processo de ensino de leitura deve ser criativo. Ele pode promover debates, exibir vídeos, realizar discussões em grupo, pesquisas sobre o tema do abordado no texto, seminários, encenações etc.

Esse tipo de atividade pode levar o estudante a se mostrar mais por meio de falas, textos escritos entre outros.

Sabe-se que é preocupante os resultados apresentados nas últimas pesquisas sobre a educação brasileira, principalmente no que se refere a leitura e interpretação de texto. Os alunos não estão lendo como deveria, este fato é comprovado todos os anos após a realização das avaliações das Provas Brasil e SAEBE, que são aplicadas nas séries finais para avaliar o nível de conhecimento e desenvolvimento nas áreas de Língua Portuguesa e Matemática.

\footnotetext{
${ }^{3}$ Ler o que não está claramente escrito ou expresso, mas pode ser entendido num texto ou discurso: li suas críticas nas entrelinhas.
} 
Mediante tais resultados a situação que já é recorrente há alguns anos é importante que seja implantado um sistema diferenciado no ensino de leitura que traga resultados positivos, como as estratégias já mencionadas anteriormente.

Sendo assim o estudante estará pronto a ser considerado um leitor competente para fazer as inferências possíveis sobre o texto lido.

À medida que se forma bons leitores supõe-se que a leitura de um discurso político não apresentará tantos problemas na questão da interpretação das informações implícitas que o texto possa ter. Todavia um texto ou discurso político, muitos não agregam conhecimento e sim trazem o interesse de muitos candidatos que se valem do discurso para conquistar os eleitores.

Todo discurso político traz um carga elevada de pretensões por parte do candidato, que convença o leitor de que a sua proposta é a melhor dentre as dos outros candidatos.

O leitor, muitas vezes, demonstra não se identificar com o tema abordado no discurso ou texto apresentado, isso significa que ele pode não gostar da área do conhecimento ou não dar importância às informações sobre o mesmo.

O leitor crítico e seguro de suas ideias e opiniões em níveis diversificados de leitura é aquele que tem consciência de que todo texto tem o sentido literal e que esse sentido o leva a perceber as informações implícitas e explícitas e que as interpretações são percebidas pelos pressupostos e subentendidos presentes no texto.

Em suma, deve-se ler as linhas e entrelinhas, pois um leitor perspicaz e competente faz as inferências necessárias a respeito do texto.

\section{METODOLOGIA}

Este artigo faz uma pesquisa qualitativa, quantitativa e com caráter bibliográfico, abrangendo os conhecimentos de autores que apresentam uma visão com soluções para deliberar os entraves no estudo do ensino de leitura a partir das inferências, as quais estão correlacionadas aos implícitos e pressupostos que estão presentes nas "entrelinhas" de cada texto que se ler. O processo de leitura precisa ser desenvolvido de forma articulada, isto é, harmonizar as ideias, questioná-las e 
condensar as informações do texto de forma clara e coerente. Apresenta análise de textos apresentando os implícitos e pressupostos que geram as inferências possíveis, assim o resultado de leituras realizadas será satisfatório e processo de leitura se tornará mais prazeroso e eficaz. A leitura precisa ser realizada com texto envolvendo qualquer temática como os discursos políticos, por exemplo, para que o leitor perceba que é preciso estar envolvido e informado sobre todos os assuntos que nos rodieam, a leitura de mundo é fundamental.

Os discursos políticos trazem informações que expressam os desejos e opiniões dos candidatos os quais, muitas vezes, não são compreendidos pelos eleitores/ouvintes visto que muitos leitores são demonstram interesse em se inteirar acerca de determinados conteúdos, porém é necessário ter um olhar mais apurado para tais textos "discursos políticos".

\section{REFERENCIAL TEÓRICO}

\section{I. $\mathrm{O}$ ensino de leitura}

O ensino de leitura é um processo que começa a partir das séries iniciais, porém a criança quando começa a frequentar a escola, ela já traz consigo várias leituras que realiza no ambiente em que vive com seus pais, irmãos, tios etc.

$\mathrm{Na}$ escola, o professor começa a associar e relacionar os conhecimentos que a criança já tem com os que ela passa a ter com a convivência com os colegas e professor na escola.

A cada ano que passa o grau de conhecimento avança e o processo de leitura va se aprimorando. Quando ela chega a séries mais elevadas, precisa se familiarizar cada vez mais com textos disponíveis nos livros didáticos e paradidáticos que são apresentados para ela, alem daqueles textos do cotidiano que fazem parte da vida de qualquer cidadão, para mantê-lo informado dos fatos e assuntos que o rodeia. Os textos que nos rodeiam estão atrelados a mutitas temáticas e os mesmos levam o leitor a refletir sobre o assunto e tirar as conclusões a partir da compreensão do mesmo. Ler não é, como num jogo de adivinhações, o sentido de um texto. É, a partir do texto, ser capaz de atribuir-lhe significado, conseguir relacioná-lo a todos os outros textos significativos para cada um, reconhecer nele o tipo de leitura que seu autor pretendia, dono da própria vontade, entrega-se a essa leitura, ou rebelar-se contra ela, pondo uma outra não prevista. (Lajolo, 200I) 
O aluno à medida que consegue expor sua opinião, ele demonstra que sabe ler, sabe argumentar sobre a temática abordada no texto, não há leitura sem interpretação, o autor do texto espera que o leitor perceba as informações explícitas e implícitas e assim realiza uma leitura de forma coerente.

\section{Discurso Político: palavra e poder}

O texto é um recurso que busca transmitir uma mensagem, passar informações que estão atreladas a valores sociais políticos, religiosos entre outros. $\mathrm{O}$ discurso político é um texto argumentativo, fortemente persuasivo, em nome do bem comum.

Esse gênero textual condiciona o leitor a fazer reflexões, pois o processo de ensino de leitura envolve vários critérios que tormnem a leitura prazerosa. É preciso desenvolver estragtégias diversificada de leitura, com leitura coletiva, individual, debates, mesa-redonda etc. Os textos utilizados nesse processo envolvem vários gêneros os quais abordam temas acerca do cotidiano e um deles é o discurso político que aboradam questões sociais envolvendo saúde, educação etc,

Os politicos fazem uso de temas para apresentar para o leitor/ eleitor possíveis soluções para os problemas que o cidadão enfrenta no seu cotidiano. Eles buscam persuadir o eleitor com apresntação de propostas para solucionar tais problemas.

Como já mensionado, os discursos politicos são do gênero argumentativo que requer do emissor a capacidade de expor de forma clara as informações e que o leitor possa compreender no ato da leitura a mensagem que o mesmo quis passar e assim possa fazer as inferências possíveis sobre o tema abordadono texto.

A leitura de textos só é realizada quando o leitor consegue compreender as informações expressas no texto e faz as inferências corretas sobre o texto lido.

Hannah Arendt (em The Human Condition) aforma que o discurso político tem por finalidade a persuasão do outro, quer para que a sua opinião se imponha, quer para que os outros admirem. 
Para isso, necessita da argumentação, que envolve, o raciocínio, e da eloquência da orientória, que procura seduzir recorrendo a afetos e sentimentos.

O discurso existe desde o início dos tempos, do início da vida do ser humano em sociedade. Na Grécia antiga, o político era o cidadão da "polis" (cidade, vida em sociedade) que, responsável pelos negócios públicos, decida tudo em diálogo na “agora" (praça onde se realizavam as assembleias dos cidadãos), mediante palavras persuasivas. Daí o aparecimento do discurso político, baseado na retórica e na oratória, orientado para convencer o povo.

É com o discurso político que o cidadão procura impor suas ideias, seus valores e projetos de forma persuasiva, usando palavras de sedução e linguagem metafórica, imagens e jogos linguísticos. Com argumentação o emissor com o seu discurso político procura persuadir seu leitor/ouvinte com promessas e decisões sobre o futuro envolvendo os problemas do cotidiano no que envolve a sociedade.

Todo discurso político é proferido em um espaço público, porém nem toda fala que é proferida é sobre política.

A antipolítica é o discurso "não sou político, sou administrador" encabeçado por sujeitos que estão envolvidos em uma causa que é de interesse de todos.

Hannah Arent apresenta uma perspectiva que distingue as atividades e ações políticas de outras açoes executadas em local público, são as antipolíticas.

Com isso surge o tatalitarismo como o regime que tudo se torna político, ressaltando que todas as coisas estão atreladas ao domínio público. Para Arendt tal regime não tem a ver com a tirania "vida privada" 4 , governo de tirano, totalitarismo ações mobilizadas na esfera pública.

Totalitarismo com dominação e fim do debate público segundo Lefort, Arendt.

\footnotetext{
O que se chama ação não é ação quando não há atores. Isto é, quando não há iniciativas que se confrontam com situações inéditas, mas apenas uma decisão do chefe, decisão que se arroga como sendo efeito do movimento da história ou da vida, que recusa a cotigência e que só exige de outrem comportamentos conformes às nomas e as resoluções".
}

\footnotetext{
4 Vida que se assemelha a tirania, o totalitarismo que busca por meio de violência o cumprimento de uma ação, obediência a qualquer custo.
} 
Ingualmente, o que se chama "fala, não é fala já que não mais circula, já que desaparece todo vestígio de diálogo, já um só, o senhor absoluto, detém o poder de dizer, ao passo que todos estão reduzidos à função de ouvir e transmitir”. (Lefort, I99I, p.68)

Política e discurso político são analisados de forma totalitarista em contrapartida com a mobilização das massas com a atividade pública desenvolvida na antiguidade.

Então Arendt diz:

\begin{abstract}
A ação que ele inicia é humanamente revelada através das palavras; e, embora o ato possa ser percebido em sua manifestação física bruta, sem o acompanhamento verbal, só se torna relevante através da palavra falada na qual o autor se identifica, anuncia o que faz, fez e pretende fazer". (ARENDET, 2008, p. 189)
\end{abstract}

O discurso e o debate deixam claro que a ação está atrelada a forma de agir e atuar dos envolvidos no processo político. A fala leva o político a agir de maneira propensa ao convencimento do leitor/ eleitor, não se pode apresentar uma proposta política sem a intenção de realizá-la, todo eleitor observa, ouve, ler e discute as propostas de candidatos para tirar as conclusões que para ele, o eleitor, serão as que trarão resultados quando estiverem em prática, após as eleições e seu candidato ganhar.

Segundo estudos realizados a partir de Aristóteles, Amossy (2005) diz que: "O lugar que engendra o etos e, portanto, o discurso, o logos do orador, e esse lugar se mostra apenas mediante as escolhas feitas por ele" (AMOSSY, 2005, p.3I).

A persuasão se dar a partir das três características que são: "logos", são os argumentos apresentados que envolvem a proposta do candidato; o "etos" é a imagem do politico que é criada para os seus eleitores e o "pathos" corresponde ao sentimento, a aproximação e a preocupação que o político nutre perante os seus eleitores para solucionar os problemas. "Vê-se que a persuasão usada pelo discurso político relaciona-se com a paixão, com a razão e com a imagem" (CHARAUDEAU, 2008b, p.93), 


\section{Discurso político: acredtiar e desacretitar}

Vive-se em mundo em que as pessoas vislumbram muitos discursos com palavras bonitas que enchem os ouvidos dos ouvintes que levam os mesmos a fantasiar e imaginar que o problema será resolvido, que não existirá mais, todavia problemas como fome, violência, educação, saúde sempre vão existir. Não há como erradicar tais problemas, eles sempre existirão.

Os políticos continuarão apresentando propostas e mais propostas aceca desses assuntos, que estarão presentes na vida das gerações que aqui estão e das gerações que estão por vir, essa é a realidade que o ser humano ouve e ouvirá sempre nos discursos políticos.

O discurso político gera debates entre candidatos adversários que expõem suas propostas de trabalho caso seja eleito. No debate são expostas as falas e as imagens dos candidatos para que as mesmas possam servir como instrumento de persuasão para o eleitor, que observará as máscaras dos candidatos e assim se constroe o "etos" e se percebe qual proposta está sendo apresentada com mais clareza e segurança para a escolha do voto de cada eleitor.

O debate é um recurso utilizado muito utilizado é a partir dele que os cadidatos a cargos públicos analisa o que pode ser dito ou não, já que a verdade muitas vezes é mascarada, eles explicitam aos seus eleitores a sua verdade dos fatos com o risco de ter sucesso ou não, a verossimilhança é o recurso que eles mais utilizam, fazem parecer verdadeiro o que pode ser apenas falácia.

Segundo Arendt, a arte de um discurso político depende do virtuosismo da execução e de uma apresentação pública. A ação política requer o agir, o fazer, a excelência no desempenho da linguagem utilizado no momento da exposição do discurso. Para Arendt:

(...) ambas as líguas possuíam dois verbos para designar aquilo que chamamos uniformemente de agir. As duas palavras gregas são árkhein: começar, conduzir e por último, gogernar; e práttein: levar a cabo alguma coisa. Os verbos latinos correspondentes são agere: pôr alguma coisa em movimento; e gerere, que é de árdua tradução e que de certo modo exprime a continuação permanente e sustentadora de atos passados de históricos (ARENDT, 2005a, p.214). 
A visão de Arendt mostra que o verbo agir em grego e em latim expressa que a ação podia gerar algo novo ou a ação estava subordinada tanto a quem começasse um ato público ou continuasse aquele ato que já existisse, assim se julgaria o senso criado por uma intersubjetividade.

O senso comum refer-se a algo que impõe em busca do controle sobre os sentidos sensoriais. A intersubjetividade é integrada a partir do senso comum, visto que cada ser confia suas particularidades a outro ser.

Assim se percebe um julgamento pode transformar a ação de um ser humano, dessa forma o espectador é o ser mais confiável das ações realizadas pelos agentes que detém o discurso.

\section{Propaganda, doutrinação e totalitarismo}

Sabe-se que os discursos que vem a público é ouvido por todos. E são vários os discursos que chegam ao conhecimento de todos, independente do meio de comunicação utilizado para tal ação. O público se coloca como lugar que serve com meio para manter a relacionção entre os homens ou a separação entre eles.

Multidões formam as massas mesmo que os homens estejam isolados e que não tenham laços sociais sem interesses comuns.

Quando o totaliarismo detém o controle absoluto, substitui a propaganda pela doutrinação e emprega a violência não mais para assustar o povo (o que só é feito nos estágios iniciais, quando ainda existe a oposição política), mas para dar realidade às suas doutrinas ideológicas e às suas mentiras utilitárias (ARENDT, I989, p. 390)

O discurso público totalitarista se assemelha a princípio a propaganda que busca êxito ao final do processo, porém o totalitarismo busca de todas as formas impor às suas doutinas ideológicas, ainda que sejam simplesmente mentiras.

A propaganda política em muitos momentos está atrelada a violência a qual se converte a doutrinação e terror para dar início ao governo totalitarista. Assim se desenvolve a propaganda.

Por meio de símbolos e ações que atuam sobre os sentidos, que causam emoções, procura-se impressionar as massas, aterrorizar os inimigos, despertar agressividade de seus próprios partidários. Além dos símbolos gráficos, plásticos e sonoros (...) são especificamente o emprego de bandeiras, uniformes, grandes manifestações, desfiles estrepitosos que 
caracterizam a propaganda deste tipo, empregada pelos ditadores (TCHAKOTINE, i967, p.354).

Além do totalitarismo as propagandas vão aparecendo e comprova-se o poder de persuasão que Tchakotine menciona.

suas modalidades são conhecidas: jornais, discursos pelo rádio, reuniões com debates, brochuras e boletins, enfim, a propaganda pessoal ou de porta em porta, quando os propagandistas vão às portas das pessoas que lhes interessam para tentar demonstrar-lhes os fundamentos de seus programas e persuadi-las a se inscrever no partido que representam ou a votar nele". (TCHAKHOTINE, I967, P. 353).

Assim constata-se que sem o poder de persuação no discurso politico não existe político, pois o mesmo precisa desse recurso para conquistar seus eleitores.

\section{Sociedade de massa e sociedade isolada}

Os homens necessitam de um lugar para se estabelecer e revelar a singularidade onde as leis criadas e os acordos firmados são aceitos. As pessoas formam uma massa homogênia que se relacionam e se distinguem já que as multidões formam a massa isolada, na qual os homens são isentos de laços sociais de caráter e interesses comuns.

A massa moderna não permeia confiança, apresenta o homem isolado sem
manter relação com os demais, ele apenas confia em si mesmo, nasua
capacidade intelectual, assim para os homens dessa massa não mantém
discurso com o cotidiano.
O que torna tão difícil suportar a sociedade de massa é o número de
pessoas que ele abrange, ou pelo menos este não é o fator fundamental;
antes, é o fator de que o mundo entre elas perdeu a força de mantê-las
juntas, de relacioná-las umas às outras e de separálas. (ARENDT, 20o8, p.
62)

A citação de Arendt demonstra que a sociedade de massaé difícil de ser aceita, mas o que a torna difícil são as leis que são ompostas para as pessoas e assim os homens perdem o espaço público para o mundo, deixando evidente que o ponto de vista exposto é apenas um, não há diversidade de ideias para que o público possa analisar e aceitar.

Dessa forma observa-se que as mudanças em relação à política foram consideráveis, porém, o objetivo continua sendo o mesmo em que o candidato coloca 
seus interesses particulares em primeiro lugar, a vontade de poder, de sentir o poder de transformar, mudar em suas mãos, e é com suas verdades ou mentiras que busca persuadir o eleitor para a concretização de seus planos.

\section{RESULTADOS E DISCUSSÃO}

Os aspectos elencados e discutidos neste artigo denotam que deseenvolver o processo de ensino de leitura é fundamental para a compreensão dos textos lidos, principalmente os discursos políticos que em muitos momentos não é atrativo para a leitura e análise já que as opiniões divergem umas das outras e para evitar discussões desagradáveis, muitos leitores optam por não ler ou ouvir debates que são proferidos por políticos ou pessoas que apoiam aquele partido ou candidato.

As pesquisas sobre leitura de gêneros textuais os quais estão inseridos os discursos políticos, deixam claro que o ensino de leiturua é de fundamental importância para a formação de leitores competentes que possam expor suas opiniões fazendo inferência aos textos lidos. Para que isso acontece é preciso que o professor esteja propenso a desenvolver atividades diversificadas de leituras com os gêneros textuais que fazem parte do cotidiano do aluno como os discursos políticos. Não é fácil, mas é preciso desenvolver o senso crítico dos estudantes para que os mesmos ao ler ou ouvir um discurso político possa dar sua opinião se expressando mediante conhecimento prévio adquirido a partir das aulas desenvolvidas apresentando as várias formas de compreensão de um discurso político.

\section{CONSIDERAÇÕES FINAIS}

O ensino de leitura é fundamental para o desenvolvimento do senso crítico para promover a interação do ser humano com o mundo que o rodeia. A escola tem um papel fundamental nesse processo. Os estudantes precisam de aulas que estimulem o gosto pela leitura, a discussão em grupo, a vontade de dizer o que pensa a respeito de temas abordados para que os meios percebam o seu papel perante a sociedade. Os temas dos textos propostos para a leituras precisam está atrelados ao cotidiando dos 
estudantes, mesmo que eles não gostem, todavia o professor tem o dever de mostrar a importancia do conhecimento do mesmo.

Os autores pesquisados e analisados trazem perspectivas diferenciadas para o estudo de ensino de leitura, mais precisamente relacionado à leitura e interpretação de discurso político, ao entendimento do que vem a ser o discurso político e ao seu objetivo. Fica evidente que as estratégias de leitura desenvolvidas não são eficazes, o texto ainda está sendo utilizado por muitos profissionais da educação como pretexto, no qual o estudante busca transcrever as informações pedidas nos enunciados, não são todos os profissionais desenvolvem que ainda desenvolve tais estratégias, porém é preciso que elas sejam inovadas e diversificadas, do contrário não serão formados leitores competentes que demostrem segurança de expor por escrito ou de forma oral seu ponto de vista a respeito da leitura realizada seja qual for o tema abordado.

Pode ser difícil chegar a resultados positivos no processo de ensino de leitura, mas é preciso pô-lo em prática, transmitir segurança para os alunos para que os mesmos se sintam seguros também e a vontade para expressar seu ponto de vista e fazer as inferências corretas sobre o texto lido.

Assim fazendo, o gosto pela leitura de textos e gêneros textuais ficará mais fácil e prazeroso. Proponha desafios, discussões, leve-os para ambientes diferenciados, realize leituras diversificadas, mostrando a realidade do dia a dia deles que eles não mais vão ver a leitura como um processo cansativo que dá sono, tédio e que é perda de tempo, mostre que o crescimento intelectual de uma pessoa requer o desenvolvimento de muitas leituras seja elas quais forem.

\section{REFERÊNCIAS}

ANGELIM, R. C. C. Polifonia e implícitos como recursos argumentativos em textos midiáticos. In: PAULIUKONIS, M A. L. \& GAVAZZI, S (Org.) Texto e discurso, mídia, literatura e ensino. Rio de Janeiro, Lucerna: 15-25

ARENDT, H. A condição humana. São Paulo: Forense Universitária e EDUSP, 2008.

Entre o passado e o futuro. São Paulo: Perspectiva $2005^{\mathrm{a}}$. 
Origens do Totalitarismo. São Paulo: Companhia das Letras, 1989.

Paz e Terra, I979.

BRICKMANN, Carlos. A vida é um palanque: os segredos da comunicação política. São Paulo: Globo, 1998.

BURKE, Peter. A fabricação do rei: a construção da imagem pública de Luís XIV. Rio de Janeiro: Zahar, 1994.

CHARAUDEAU, Patrick. Discurso Político. São Paulo: Contexto, 2018.

CITELLI, Adilson. Linguagem e persuasão. São Paulo: Ática, 2004.

LEFORT, Claude. "Hannah Arendt e a questão do político". In: Pesando o político: ensaio sobre democracia, revolução e liberdade. Rio de Janeiro: Paz e Terra, 199I

LEFORT, Claude (199I). Pensando o político: ensaios sobre democracia, revolução e liberdade. Rio de Janeiro: Paz e Terra.

TCHAKHOTINE, Serge. A mistificação das massas pela propaganda política. Rio de Janeiro: Civilização Brasileira, 1967. 